\title{
Observation of Sea Water Droplets by Filter Paper*
}

\author{
Yoshiaki ToBA**
}

\begin{abstract}
A general notice on the method to measure the size of water drops by filter paper is first described. Then the process of preparation of a dye-treated filter paper, which is suitable for the observation of sea water droplets, is reported.
\end{abstract}

\section{Methods of Observation of the Size of Water Drops}

For estimation of the size of water drops, several methods have been so far employed, including the flour-method to measure a doughpellet which is formed by a water drop when it fell into fine, uncompacted flour (W.A. BENTLEY 1904), the use of a sooted screen by measuring the round mark formed on it after a water drop:passed it (D.C. BLANCHARD $1946 \mathrm{~b}$ ), photographic measurements, and the use of filter paper.

It is said that the method to estimate the drop size from the area which is occupied by absorbed water of a drop on filter paper, was introduced by J. WIESNER (1895). Later, some sort of dyes came to be used for preserving the stains on the filter paper. Some sprinkled dye powder over the filter paper, others dyed the water itself previously before experiments were carried out, while the other treated the filter paper with dyes so that it was dyed at the very spot where a water drop fell. As to dyes, eosine (P. Lenald 1904 ; A. Defant 1905), water soluble, blue, anilin dye (R.H. MAGARVEY 1957), potassium permanganate (L.J. ANDERSON 1948), gentianviolet dye (J.S. MARSHALL et al 1947), methylene blue dye (D.C. Blanchard 1953) and others were used for fresh water drops.

To measure sea water drops, BLANCHARD and Woodcock (1957) used methylen blue dye by dying the sea water itself. S.G. BoycE (1951) used a filter paper which was dipped in $0.01 \mathrm{~N} \mathrm{~K}_{2} \mathrm{CrO}_{4}$, then dried in $0.02 \mathrm{~N} \mathrm{AgNO}_{3}$, subsequently put in distilled water to remove

\footnotetext{
* Received August 1, 1958.

** Geophysical Institute, Kyoto University.
}

the exess $\mathrm{AgNO}_{3}$ and redried. This filter paper leaves light-yellow spots by sea water droplets.

The filter paper method has been used by many investigators, especially, for the observation of rain drops. It has been confirmed since WIESNER that a filter paper must be of the same standard, that it must be as homogeneous as possible and that it should be dried sufficiently before it receives water drops, and it has been further roticed that the settling velocity of a drop affects the spot size for drops lager than about $0.7 \mathrm{mg}$ in weight, or about $1.3 \mathrm{~mm}$ in diameter (L.J. ANDERSON 1948 ; R.T. JARMAN 1956 ; R.H. MAGARVEY 1957) .

Now, let $M$ denote the drop volume in $\mathrm{mm}^{3}$, $A$ : the area of a spot in $\mathrm{mm}^{2}$, and $\alpha$ and $\nu$ : the thickness in $\mathrm{mm}$ and the porosity of the filter paper, then it is

$$
M=\alpha \nu A
$$

As spots left on filter paper generally have an elliptic form, it follows that

$$
M=C_{1} D^{a}
$$

or

$$
d=C_{2} D^{b}
$$

where $D$ is the longer diameter of a spot in $\mathrm{mm}, d$ is the diameter of a drop assumed as sphere in $\mathrm{mm}$, and $C_{1}, C_{2}, a$ and $b$ are numerical constants. It is theoretically inferred that $a$ equals 2 and $b$ equals $2 / 3$. By direct measurement of $d$ and $D$, one may obtain $C_{1}$ and $C_{2}$ for his filter paper.

Recently, R.T. JARMAN (1956) examined the spreading area of water on a filter paper and obtained the value of $b=0.84 \pm 0.02$, and pointed out that the value of $b$ is not in all cases 2/3. R.H. MagaRVEY (1957) obtained, for his case, the following relation for water drops 
between $0.5 \mathrm{~mm}$ and $10.5 \mathrm{~mm}$ in diameter,

$$
\begin{aligned}
& d=\frac{1}{3} D^{0.75} \quad(d>1.5), \\
& d=\frac{1}{3} D^{0.93} \quad(d<1.5) .
\end{aligned}
$$

Thus, it should be kept in mind that the value of $b$ may be varied according to the kind of liquid forming a drop, the nature of filter paper used, the relation between drop size and paper thickness, and especially for large drops, condition of drying during absorbtion of water, or the settling velocity of a drop, and so forth.

In our country, $\mathrm{H}$. Maruyama and K. Hama (1954) proposed a method of observing precipitation such as rain, snow etc. by using water blue and Toyo Filter Paper No. 1511. The last two figures of the number specifying this paper represent the thickness of the paper. So, in this case, it has the thickness of $0.11 \mathrm{~mm}$. Water blue was milled to fine powder and was suspended in benzine petroleum. The filter paper was passed through the suspension, and dried. Thus the dye particles were scattered uniformly in the fibrous tissue and fixed there. Water drops that fell upon it, formed blue spots of elliptic shape on the paper. They obtained from direct observations, the relationship,

$$
\alpha \nu=0.0343
$$

and from measurement of the drops of $a^{\prime}=0.4$ to $6(C=2$ to 70$)$,

$$
M=0.0230 D^{2}
$$

and

$$
d=0.353 D^{\frac{2}{3}}
$$

On this filter paper, however, only faint marks are formed by droplets of sea water. Probably, this is due to the fact that water blue dissolves very little in sea water owing to salting out. Attempts to vanish salting out by using some surface active agents, and tests on various dyes were carried out in our laboratory, but the dyes suitable to the sea water were not many. Only the following treatment of filter paper seems to be suitable for sea water droplets.

\section{The Process of Preparation and the Use of Dye-Treated Filter Paper}

About $2 \mathrm{gm}$ of Nippon Sky Blue 380\% (direct sky blue $5 \mathrm{~B}$; manufactured by Sumitomo. Chemical Co., LTD.) are crushed in a mortar under the presence of such a quantity of ethanol as immerse the dye powder. In the course, ethanol is added three or four times during thirty or forty minutes. Then, it is poured into a small beaker by rinsing the mortar with exess ethanol of about $20 \mathrm{cc}$. In tens of minutes, the dye particles precipitate considerably, and dark red fluid is left. After leaving it one or two days, the superficial dark red fluid is removed as completely as possible, softly with an injector, and the sediment is poured into a large beaker containing benzine ptroleum of about $400 \mathrm{cc}$ in which surface active agent of about one per cent in weight of benzine petroleum is dissolved, and stirred. By this process, dye particles suspend fairly well in benzine petroleum. After leaving for a few tens of minutes, it is poured into an enameled dish. Toyo Filter Paper No. $1511(20 \mathrm{~cm} \times 20 \mathrm{~cm})$ is passed through the suspension quickly piece by piece, and dried. As the benzine petroleum in the dish evaporates, it has to be replenished in due quantity. While $300 \mathrm{cc}$ of the liquid is supplied, 50 pieces of the dye-treated filter paper are prepared.

For a surface active agent which keeps the dye particles in suspension, powdered matter is desired, and Neogen Powder (40\% of Naalkylbenzene-sulfonate is contained; Dai-ichi Kogyo Seiyaku Co., LTD., Kyoto) gave the finest result in our experiment.

The prepared filter paper leaves distinct marks by sea water droplets. Moreover, we can easily distinguish the stains by sea water droplets from those by fresh water droplets: the former are uniformly colored, while the latter are enclosed ty links of dark color near the borders (Fig. 1).

If we determine the coefficients in equation (2) and (3) in the manner described in the next section, we can determine the size of the original sea water droplets, by means of the longer diameters of the stains on the paper. 


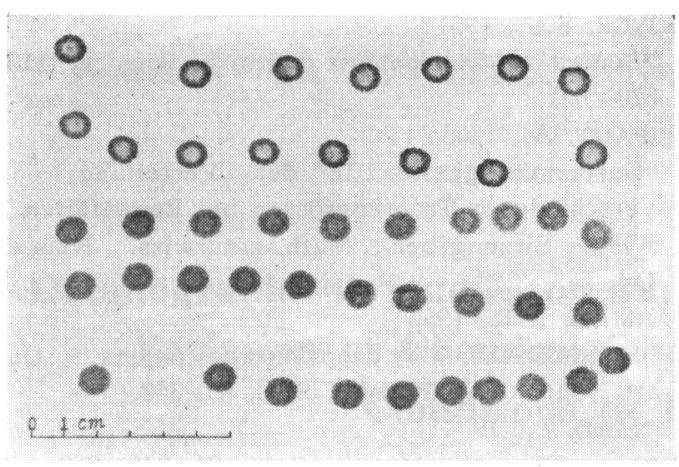

Fig. 1. The difference between the marks by sea water drops and those by fresh water drops. The upper two ranks are the stains by fresh water droplets, and the lower three ranks are those by sea water droplets.

The diameters of the stains can easily be measured by a reading microscope with $1 / 20$ $\mathrm{mm}$ vernier. When the size distribution of a number of drops is desired, it may be conveniently obtained by the scale which is marked with the values of $D$ corresponding to $d$, for example, of $0.15 \mathrm{~mm}, 0.25 \mathrm{~mm}, 0.35 \mathrm{~mm}, \ldots \ldots$, successively.

Character of this paper does not sensibly change for ordinary preservation, but it is desired to be preserved in dry places.

The marks by sea water droplets on this paper are very distinct, and it is readily used for ordinary sea water droplets. Examples of the application of the paper will be published in a succeeding report concerning the drop production by the bursting of air bubbles on the sea surface.

\section{The Determination of the Coefficients and} the Range of Application of the Paper

The constants in equation (2) and (3) may vary according to the kind and quantity of the dye or of the surface active agent used, or to the salinity of the drops. It is desirable, therefore, that the constants are determined by the user for his own case. Since MaruYAMA and HAMA showed already that the relationships (4) and (5) hold over a fairly wide range of $M$, it may be sufficient to determine the coefficients $C_{1}$ and $C_{2}$ by the values of $M$ for some range of drop diameter, assuming $a$ and $b$ to be 2 and $2 / 3$, respec- tively.

By using a microburette, $M$ or $d$ is determined, and by actually measuring the corresponding $D$, we may obtain $C_{1}$ and $C_{2}$ from the relations,

$$
C_{1}=M / D^{2}
$$

and

$$
C_{2}=\left(6 C_{1} / \pi\right)^{\frac{1}{3}}
$$

The author determined the coefficients for the paper above described for sea water droplets, and the values $C_{1}=0.027, C_{2}=0.37$ were obtained. For fresh water drops, $C_{1}=0.034$ and $C_{2}=0.40$ were also obtained.

The droplets larger than $0.2 \mathrm{~mm}$ in diameter can be measured sufficiently by the paper. To estimate the effect of salinity, stains were made by droplets of various salinity. Fig. 2 illustrates them, showing that the filter paper can well be used within the salinity range of from 0 to 100 per mille.

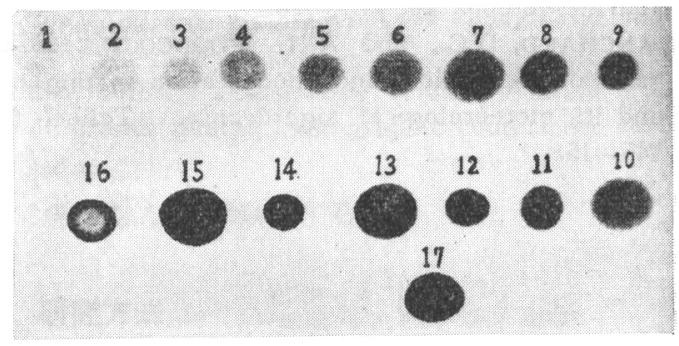

Fig. 2. The variation of the nature of the stains with salinity. The salinity of droplets are as follows:-Nos. $1(200), 2$ (180), $3(160), 4(140), 5(120), 6(100), 7$ (90), $8(80), 9(70), 10(60), 11(50), 12(40)$, $13(30), 14(20), 15(10), 16(0), 17$ (34.7 : sea water). (The figures in parentheses. are salinity in per mille.)

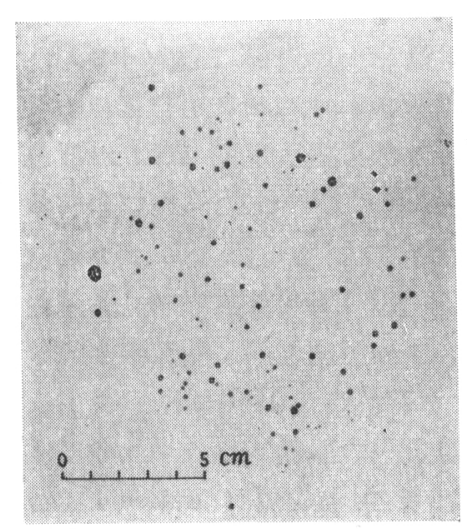

Fig. 3. Examples of application to the observation of sea water droplets produced by bursting of air bubbles on the sea water surface. 


\section{Acknowledgements}

The author wishes to express his hearty gratitude to Prof. Dr. S. HAYAMI for his cordial guidance and encouragement throughout the course of this investigation. Thanks are also due to Dr. Z. YoSHIDA of Department of Industrial Chemistry of Kyoto University, for his numerous advice.

\section{References}

ANDERSON, L.J. 1948:

"Drop-size distribution measurements in orographic rain." Bull. Ameri. Meteor. Soc., 29, $362-$ 366. BENTLEY, W.A., 1904 :

"Studies of raindrops and raindrop phenomena." Month. Weath. Rev., 32, 450-456.

BLANCHARD, D.C., 1949b :

"The use of sooted screens for determining raindrop size and distribution." Schenectady, Genl. Elect. Res. Lab. (Occas. Rep. 16, Project Cirrus), $11 \mathrm{pp}$.

BLANCHARD, D.C., 1953 :

"Raindrop size-distribution in Hawaiian rains." Journ. Meteor., 10, 457-473.

BLANCHARD, D.C., and A.H. WOODCOCK, 1957 : "Bubble formation and modification in the sea and its meteorological significance." Tellus, 9, $145-158$.
BOYCE, S.G., 1951 :

"Source of atmospheric salts." Science, 113, $620-621$.

DEFANT, A., 1905 :

"Gesetzmässigkeiten in der Verteilung der Verschiedenen Tropfengrössen bei Regenfällen." Wiener Sitzungsber., Math.-naturwiss. Klasse, 114, 585-646.

JARMAN, R.T., 1956 :

"Stains produced by drops on filter papers." Quart. Journ. Roy. Meteor. Soc., 82, 352.

LENARD, P., 1904:

"Über Regen." Meteor. Zeit., 21, 249-262.

MAGARVEY, R.H., 1957 :

"Stain method of drop-size determination." Journ. Meteor., 14, 182-184.

MARSHALL, J.S., R.C. LANGILLE, and W. McK. PALMER, 1947 :

"Measurement of rainfall by rader.' Journ. Meteor., 4, 186-192.

MARUYAMA, H., and K. HAMA, 1954 :

"Successive observation of rain drops, snowflakes and others." Tenki, 1, 50-52. (In Japanese)

WIESNER, J., 1895 :

“Beiträge zur Kenntnis des tropischen Regens.'

Wiener Sitzungsber., Math.-naturwiss. Klasse, 104, 1937. 